\title{
Neutrophil elastase: alpha-1-proteinase inhibitor complex in serum and bronchoalveolar lavage fluid in patients with pulmonary fibrosis
}

\author{
H. Yamanouchi*, J. Fujita*, S. Hojo*, T. Yoshinouchi**, T. Kamei+, I. Yamadori++, \\ Y. Ohtsuki\#, N. Uedas, J. Takahara*
}

Neutrophil elastase: alpha-1-proteinase inhibitor complex in serum and bronchoalveolar lavage fluid in patients with pulmonary fibrosis. H. Yamanouchi, J. Fujita, S. Hojo, T. Yoshinouchi, T. Kamei, I. Yamadori, Y. Ohtsuki, N. Ueda, J. Takahara. @ERS Journals Ltd 1998.

ABSTRACT: It was hypothesized that neutrophil elastase released from activated neutrophils may play an important role in the pathogenesis of pulmonary fibrosis.

In the present study, we measured the neutrophil elastase:alpha-1-proteinase inhibitor complex (E-PI) in serum and bronchoalveolar lavage fluid (BALF) in 26 patients with pulmonary fibrosis and evaluated the correlation between E-PI levels and several parameters.

E-PI levels in serum of patients with pulmonary fibrosis $\left(635.8 \pm 112.0 \mathrm{ng} \cdot \mathrm{mL}^{-1}\right)$ were significantly elevated compared to normal nonsmokers $\left(122.0 \pm 4.0 \mathrm{ng} \cdot \mathrm{mL}^{-1}\right)$ as well as normal smokers $\left(132.8 \pm 8.4 \mathrm{ng}^{\circ} \mathrm{mL}^{-1}\right)(\mathbf{p}<0.01)$. E-PI levels in serum significantly correlated with hepatocyte growth factor (HGF) levels in serum, C-reactive protein $(\mathrm{CRP})$, and negatively correlated with arterial oxygen tension $\left(\mathrm{Pa}_{\mathrm{a}} \mathrm{O}_{2}\right)$, and arterial carbon dioxide tension $\left(\mathrm{P}_{\mathrm{a}}, \mathrm{CO}_{2}\right)$. E-PI/albumin levels in BALF significantly correlated with HGF/albumin levels in BALF, lactate dehydrogenase (LDH)/albumin in BALF, total number of inflammatory cells (alveolar macrophages and neutrophils) in BALF, and several markers derived from epithelial cells in BALF.

Our data demonstrated: 1) neutrophil elastase:alpha-1-proteinase inhibitor complex in serum increased in patients with pulmonary fibrosis; and 2) neutrophil elastase:alpha-1-proteinase inhibitor complex in serum and bronchoalveolar lavage fluid correlated with clinical parameters in pulmonary fibrosis. These results suggest that neutrophil elastase may play a significant role in the process of lung injury in pulmonary fibrosis.

Eur Respir J 1998; 11: 120-125.
*First Dept of Internal Medicine, Kagawa Medical University, Kagawa. **Dept of Internal Medicine, Matsuyama Citizen Hospital, Ehime. +Dept of Internal Medicine, Kagawa Prefectural Central Hospital, Kagawa. +Dept of Pathology, Okayama University Medical School, Okayama. \#Second Dept of Pathology, Kochi Medical

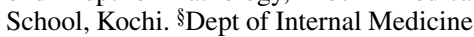
Ehime Prefectural Central Hospital,

Ehime, Japan.

Correspondence: J. Fujita

First Dept of Internal Medicine

Kagawa Medical University

1750-1 Miki-cho

Kita-gun

Kagawa 761-07

Japan

Fax: 0081878912147

Keywords: Collagen vascular disorder idiopathic pulmonary fibrosis

neutrophil elastase:alpha-1-proteinase

inhibitor complex

pulmonary fibrosis

Received: March 171997

Accepted after revision October 81997
Idiopathic pulmonary fibrosis (IPF) and pulmonary fibrosis associated with a collagen vascular disorder (PF-CVD) are inflammatory lung diseases of unknown aetiology that are characterized by the accumulation of neutrophils and mononuclear cells $[1,2]$. Increasing scientific evidence suggests a role for neutrophils in the pathogenesis of pulmonary fibrosis. Increases in polymorphonuclear neutrophils in bronchoalveolar lavage fluid (BALF) [2-7] and in lung tissue [8] have been demonstrated in patients with IPF.

Neutrophil elastase, a powerful protease released by neutrophils, destroys the extracellular matrix, modifies airway epithelial cells and interferes with respiratory host defence mechanisms [9]. In vivo, neutrophil elastase is normally regulated by the serum antiproteinase, alpha-1-proteinase inhibitor (alpha-1-PI), which inactivates the free enzyme by rapidly forming complexes with it [10].

Although the local elastase and alpha-1-PI balance has been extensively studied in bronchoalveolar lavage (BAL) in patients with pulmonary emphysema $[11,12]$ and adult respiratory distress syndrome (ARDS) $[13,14]$, there have been relatively few investigations in patients with pulmonary fibrosis [15, 16]. BoRzi et al. [15] reported the elevation of serum elastase in patients with IPF and its correlation with disease severity. GARCIA et al. [16] reported that levels of elastase in BALF are strongly correlated with a diminished diffusion capacity and a reduced forced vital capacity (FVC).

We hypothesized that if neutrophil elastase plays a significant role in the pathogenesis of pulmonary fibrosis, its values in serum or BALF should correlate with other clinical parameters.

\section{Materials and Methods}

\section{Subjects}

The protocols of this study were approved by the institutional review board for human studies and informed written consent was obtained from the subjects. We studied 20 patients with a diagnosis of pulmonary fibrosis in Kagawa Medical Hospital (613 beds) and Matsuyama Citizen Hospital (538 beds) from 1990-1996. Of the 20 patients, 14 had IPF and six had PF-CVD, three had rheumatoid arthritis, two had dermatomyositis, and one had Sjogren syndrome. The patients (11 males and nine females) 
had a median age of 68 yrs (range 44-86 yrs). There were 11 nonsmokers, two exsmokers, and seven current smokers. The diagnoses were made by clinical, radiological, physiological, and histological analyses. The criteria used included: history of exertional dyspnoea and cough; fine crackles on physical examination; compatible findings on the chest radiograph (diffuse basal reticulonodular shadowing); physiological abnormalities of restrictive lung defects including decreased diffusing capacity; and abnormal arterial oxygen tension $\left(\mathrm{Pa}_{\mathrm{a}} \mathrm{O}_{2}\right)$ at rest and/or with exertion. Histological confirmation was obtained in all cases by open lung biopsy. The histology of all patients with PF-CVD had the pattern of usual interstitial pneumonia (UIP). In all patients, high resolution computed tomographic (HRCT) scanning of the lungs was performed [2, 17]. All patients received no immunosuppressive treatment such as corticosteroid or cyclophosphamide. We also studied 15 normal smokers (smoking at least 1 pack $\cdot$ day $^{-1}$ ) with median age of $55 \mathrm{yrs}$, and 15 normal subjects, with a median age of 55 yrs. None of the subjects had a history of lung disease, no clinical findings suggested lung disease and liver and renal functions were normal. They all had normal chest radiographs and their pulmonary function test results were within the normal range. The 15 normal smokers could all undergo BAL analyses.

\section{Blood samples}

Peripheral venous blood samples with and without ethylenediaminetetra-acetic acid (EDTA) were obtained before breakfast. After centrifugation at $1,000 \times \mathrm{g}$ for $10 \mathrm{~min}$ at $4^{\circ} \mathrm{C}$, the serum was frozen and stored at $-70^{\circ} \mathrm{C}$ until used. Arterial blood samples were analysed for $\mathrm{Pa}_{\mathrm{a}} \mathrm{O}_{2}$ and arterial carbon dioxide tension $\left(\mathrm{Pa}_{\mathrm{a}} \mathrm{CO}_{2}\right)$ using a blood gas analyser.

\section{$B A L$}

After the upper airway was anaesthetized with topical lidocaine, a flexible fibreoptic bronchoscope was wedged into the lower respiratory tract. To sample the lower respiratory tract, BAL was performed by infusing three $50 \mathrm{~mL}$ aliquots of sterile saline at the site of the anterior segment of the right lower lobe. The last two aliquots were saved for evaluation. The fluid was filtered through gauze, and cells were separated from alveolar lavage fluid by centrifugation $(300 \times \mathrm{g}$ for $10 \mathrm{~min})$. BALF was frozen and stored at $-70^{\circ} \mathrm{C}$ until used.

Measurement of elastase: alpha-1-PI complex (E-PI) levels in serum and BALF and correlations with other parameters

At first, free elastase activity in BALF was measured using a synthetic substrate, methoxysuccinyl-L-alanyl-L-alanyl-L-prolyl-L-valine p-nitroanilide. As free elastase activity was not detected in all BALF samples, we used E-PI levels to evaluate elastase burden in both serum and BALF [11]. E-PI concentration was determined using enzyme-linked immunosorbent assay (ELISA) kits (Diagnostica Merck,
Darmstadt, Germany) as described in detail by Neumann and co-workers [18, 19]. Briefly, the samples were added to wells coated with sheep anti-neutrophil elastase immunoglobulin (Ig)G. This antibody does not cross-react with cathepsin $\mathrm{G}$ or other neutrophil proteinases. After incubation and washing, the solid phase-bound E-PI were further incubated with alkaline phosphatase-labelled rabbit anti-alpha1-PI IgG. After further washings, p-nitrophenylphosphate was added to measure the amount of solid phase-bound E-PI. This assay was calibrated using a standard solution of known E-PI concentration. The lower detection limit of this assay was $2.5 \mathrm{ng} \cdot \mathrm{mL}^{-1}$. Data were expressed as mean values from duplicate determinations.

Peripheral blood samples were measured for white blood cell (WBC) counts and erythrocyte sedimentation rate (ESR). The serum samples were analysed for hepatocyte growth factor (HGF), E-PI, C-reactive protein (CRP), lactate dehydrogenase (LDH), and IgG. The BALF samples were analysed for HGF, E-PI, LDH, carcinoembryonic antigen (CEA), carbohydrate antigens sialyl Lewis (CA) 199, squamous cell carcinoma related antigen (SCC), IgG, IgA, albumin, and cellular profiles. HGF was measured by ELISA with monoclonal and polyclonal antibodies against human HGF (Otsuka Assay Laboratories, Tokushima, Japan). Tumour markers were measured by radioimmunoassay. Data in BALF were corrected by albumin (divided each datum by predicted albumin concentration). Pulmonary function measurements, vital capacity $\%$ predicted (VC) and forced expiratory volume in one second (FEV1) as a percentage of forced vital capacity were obtained for all patients.

E-PI levels in serum and BALF were also measured in normal smokers and compared with the results of patients with pulmonary fibrosis. In patients with pulmonary fibrosis, correlations between each parameter was evaluated.

\section{Statistical methods}

Results were expressed as mean values \pm SEM. Comparisons of values between two groups were analysed with the Mann-Whitney U-test. Correlations were evaluated using the Pearson's correlation coefficient, and Fisher's $r$ to $\mathrm{Z}$ method was used to calculate the p-values. A p-value of less than 0.05 was considered significant.

\section{Results}

Figure 1 shows the E-PI levels in: 1) serum; and 2) BALF of normal nonsmokers, normal smokers, and patients with pulmonary fibrosis. E-PI levels in the serum of patients with pulmonary fibrosis $\left(635.8 \pm 112.0 \mathrm{ng} \cdot \mathrm{mL}^{-1}\right)$ were significantly elevated compared to normal nonsmokers $\left(122.0 \pm 4.0 \mathrm{ng} \cdot \mathrm{mL}^{-1}\right)$ and normal smokers $(132.8 \pm 8.4$ $\left.\mathrm{ng} \cdot \mathrm{mL}^{-1}, \mathrm{p}<0.01\right)$. E-PI/albumin levels in BALF of patients with pulmonary fibrosis $\left(139 \pm 44 \mathrm{ng} \cdot \mathrm{mg}\right.$ albumin $\left.{ }^{-1}\right)$ were not increased (although, this was nonsignificant) compared to normal nonsmokers $\left(83 \pm 29 \mathrm{ng} \cdot \mathrm{mg}\right.$ albumin $\left.{ }^{-1}\right)$ and normal smokers $\left(156.3 \pm 34 \mathrm{ng} \cdot \mathrm{mg}\right.$ albumin $\left.{ }^{-1}\right)$. Figure 2 shows that E-PI levels in serum significantly correlated with: 1) HGF levels in serum $(\mathrm{r}=0.567, \mathrm{p}<0.01)$; and 2) CRP $(\mathrm{r}=0.537, \mathrm{p}<0.05)$, but negatively correlated with 3) $\mathrm{Pa}_{\mathrm{a}} \mathrm{O}_{2}(\mathrm{r}=-0.513, \mathrm{p}<0.05)$ and 4) $P \mathrm{a}, \mathrm{CO}_{2}(\mathrm{r}=-0.574$, $\mathrm{p}<0.01$ ) in patients with pulmonary fibrosis. Figure 3 shows 


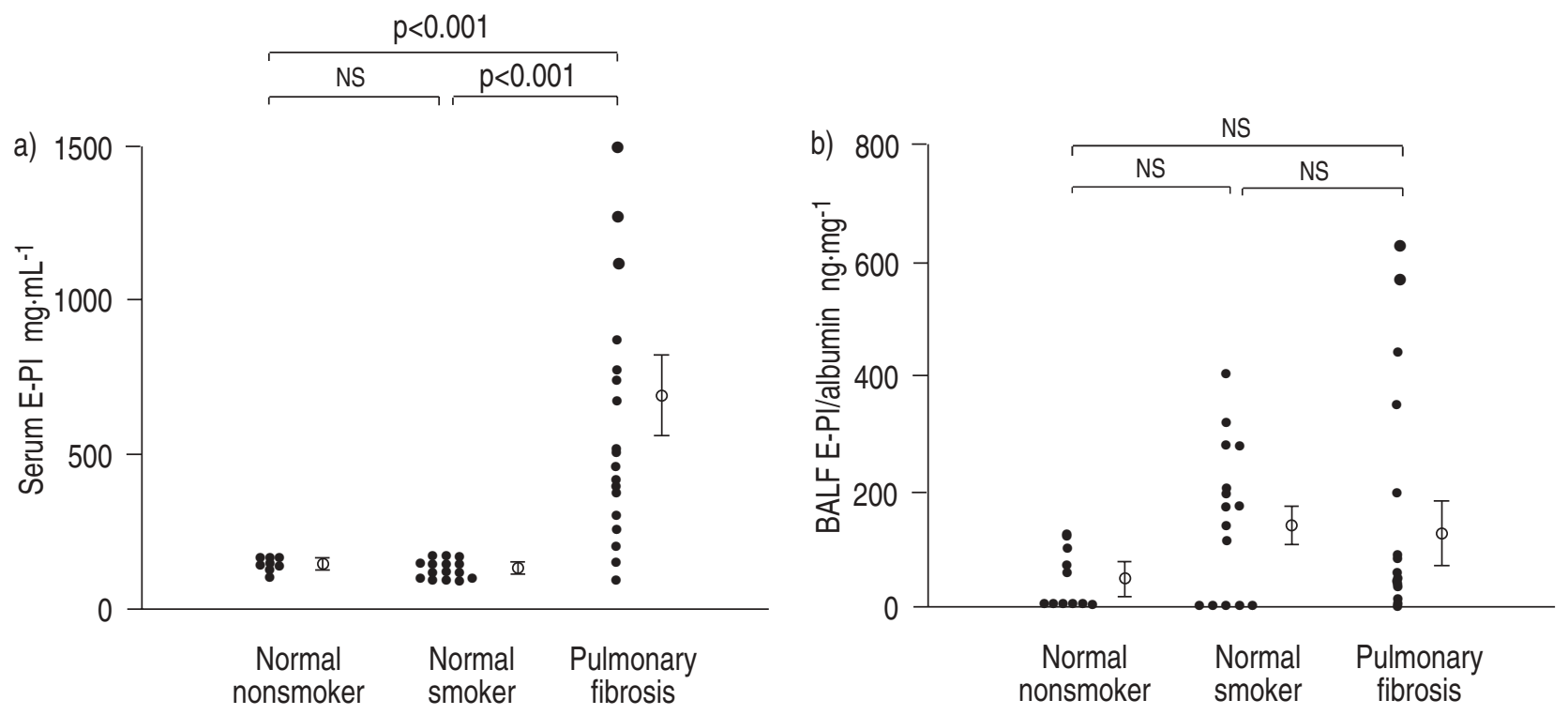

Fig. 1. - Elastase:alpha-1-proteinase inhibitor complex (EPI) levels in: a) serum; and b) bronchoalveolar lavage fluid (BALF) in normal nonsmokers, normal smokers, and patients with pulmonary fibrosis. Open symbols and bars represent the mean \pm SEM. Ns: nonsignificant.
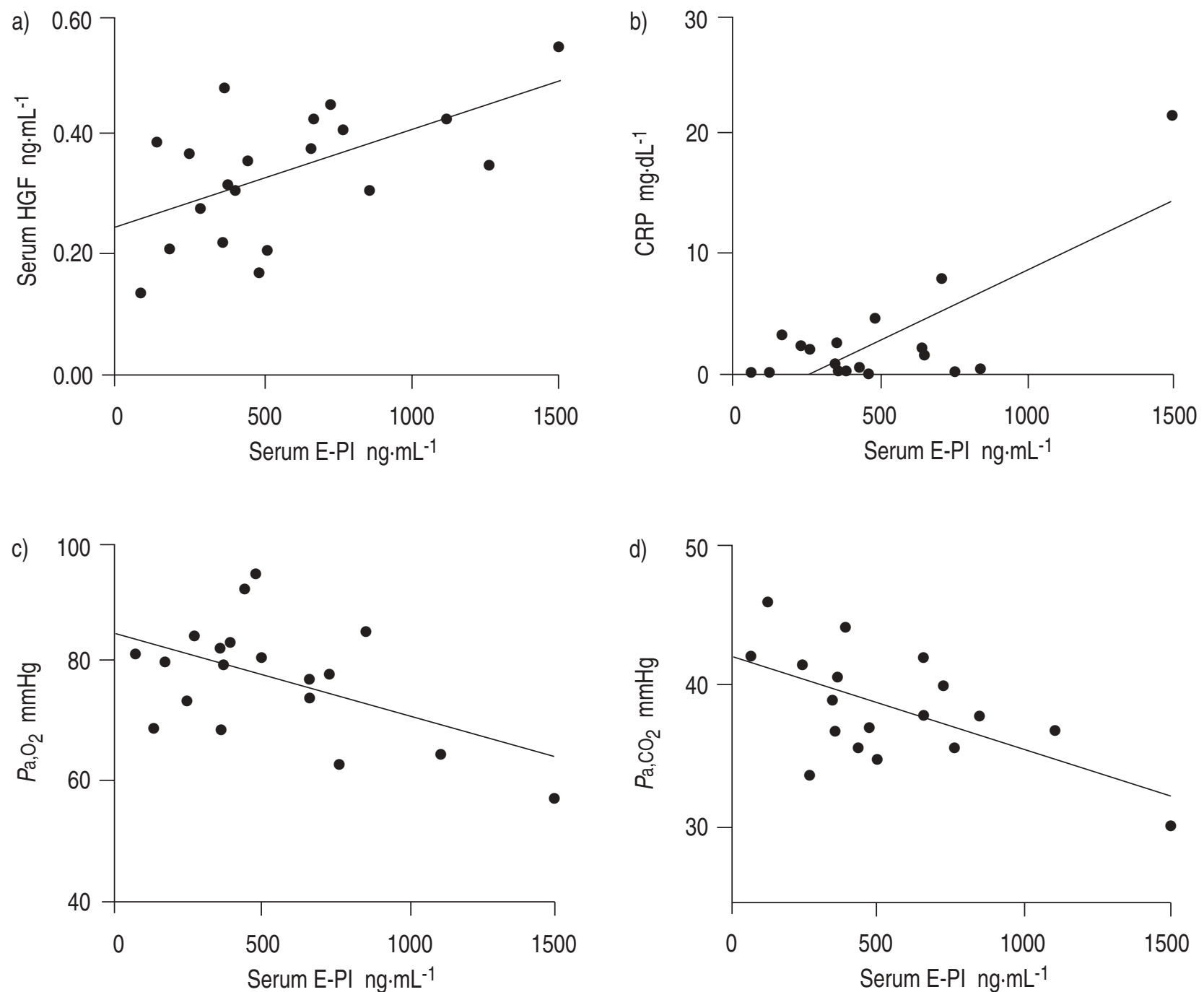

Fig. 2. - Correlations between elastase:alpha-1-proteinase inhibitor complex (E-PI) in serum levels in patients with pulmonary fibrosis and: a) hepatocyte growth factor $(\mathrm{HGF}) ; \mathrm{b}) \mathrm{C}$-reactive protein $(\mathrm{CRP}) ; \mathrm{c})$ arterial oxygen tension $\left(\mathrm{Pa}_{\mathrm{a}} \mathrm{O}_{2}\right)$; and d) arterial carbon dioxide tension $\left(P \mathrm{a}, \mathrm{CO} \mathrm{O}_{2}\right)$. 1 $\mathrm{mmHg}=0.133 \mathrm{kPa}$. 

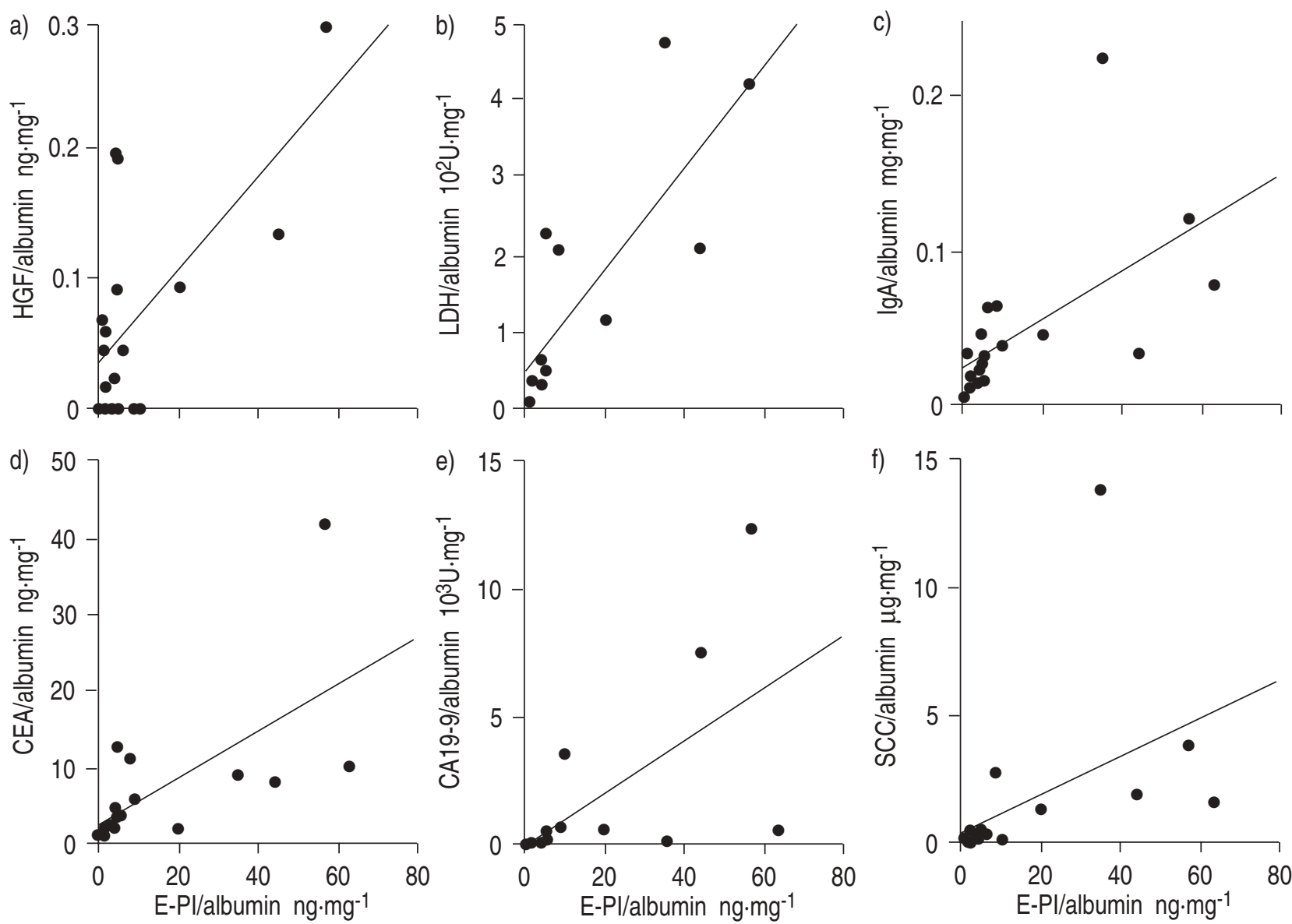

Fig. 3. - Correlations between elastase:alpha-1-proteinase inhibitor complex (E-PI)/albumin levels in bronchoalveolar lavage fluid in patients with pulmonary fibrosis and: a) hepatocyte growth factor (HGF)/albumin; b) lactate dehydrogenase (LDH)/albumin; c) immunoglobulin (Ig)A/albumin; d) carcinoembryonic antigen (CEA)/albumin; e) carbohydrate antigens sialyl Lewis (CA19-9)/albumin; and f) squamous cell carcinoma (SCC)/albumin.
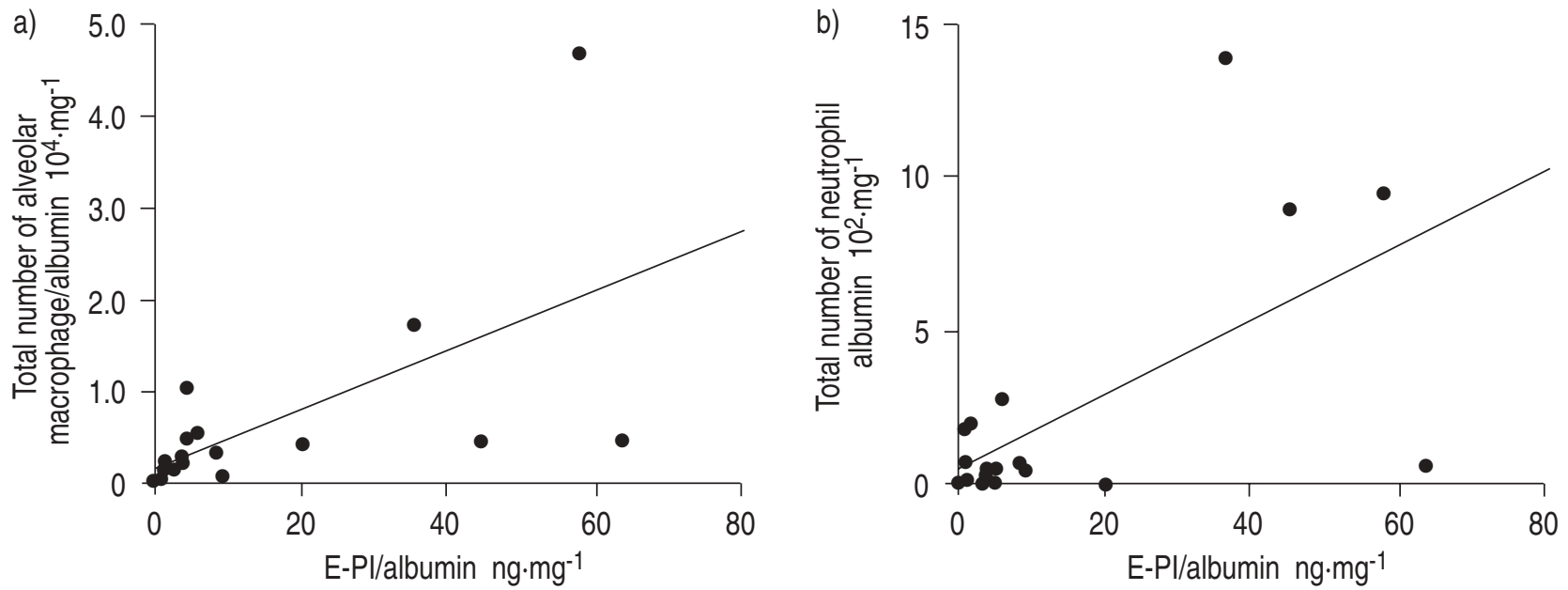

Fig. 4. - Correlations between elastase:alpha-1-proteinase inhibitor complex in bronchoalveolar lavage fluid in patients with pulmonary fibrosis and: a) total number of alveolar macrophage/albumin; and b) total number of neutrophil/albumin.

that E-PI/albumin levels in BALF significantly correlated with: 1) HGF/albumin levels ( $\mathrm{r}=0.707, \mathrm{p}<0.0005) ; 2$ ) LDH/albumin ( $\mathrm{r}=0.808, \mathrm{p}<0.0005)$; 3 ) several markers derived from epithelial cells (IgA/albumin $(\mathrm{r}=0.605$, $\mathrm{p}<0.005)$; 4) CEA/albumin ( $\mathrm{r}=0.662, \mathrm{p}<0.001)$; 5) CA19-9/albu$\min (\mathrm{r}=0.653, \mathrm{p}<0.005)$; and 6) SCC/albumin $(\mathrm{r}=0.476, \mathrm{p}<$ 0.05). Figure 4 shows that E-PI/albumin levels in BALF were found to significantly correlated with: 1) total num- ber of inflammatory cells (alveolar macrophage/albumin $(\mathrm{r}=0.620, \mathrm{p}<0.005)$; and 2) total number of neutrophil/ albumin $(\mathrm{r}=0.626, \mathrm{p}<0.005)$ in patients with pulmonary fibrosis.

\section{Discussion}

In the present study, it was demonstrated that serum levels of E-PI in patients with pulmonary fibrosis were 
significantly higher than those of normal smokers, and E-PI in serum and BALF were significantly correlated with some clinical parameters in patients with pulmonary fibrosis.

IPF and PF-CVD are chronic inflammatory lung diseases of unknown aetiology that are characterized by the accumulation of neutrophils, macrophages, lymphocytes, and/or eosinophils $[1,2]$. These are followed by the progressive deposition of collagen within the interstitium and subsequent destruction of lung airspace. Increases in polymorphonuclear neutrophils in BALF and in lung tissue have been demonstrated in patients with pulmonary fibrosis [20]. Therefore, pulmonary fibrosis is considered to be associated with a neutrophilic alveolitis, and neutrophils may play an important role in the pathogenesis of the lung injury.

There are a few studies that have evaluated the clinical significance of neutrophil elastase in patients with pulmonary fibrosis. In patients with IPF, the levels of polymorphonuclear cell elastase are higher than in control subjects and patients with sarcoidosis, and have a strong correlation with serum copper/zinc superoxide dismutase [15]. In patients with rheumatoid interstitial lung disease, GARCIA et al. [16] showed that significant correlations are found between physiological parameters and the percentage of BAL neutrophils, and that the levels of human neutrophil elastase are strongly correlated with diminished diffusion capacity and reduced FVC.

In the present study, although E-PI levels in serum in patients with pulmonary fibrosis were significantly higher than normal smokers, there was no significant difference in E-PI levels in BALF between patients with pulmonary fibrosis and normal smokers. This evidence might suggest that: 1) E-PI in BALF in patients with IPF leaks more easily to serum because of the damage of the capillary-endothelial barrier; or 2) neutrophilic endotheliitis takes place in patients with pulmonary fibrosis.

Correlations were demonstrated between E-PI levels in serum and CRP, $\mathrm{Pa}, \mathrm{O}_{2}$, and $\mathrm{Pa}_{\mathrm{a}} \mathrm{CO}_{2}$. This evidence suggested that E-PI levels in serum reflected the disease activity in patients with pulmonary fibrosis. Correlation between E-PI in serum and HGF in serum and correlations between E-PI/albumin levels in BALF and HGF/albumin levels in BALF seemed to be interesting. As HGF is believed to play an important role in the process of lung regeneration, HGF in serum might increase in response to the excess of neutrophil elastase.

E-PI/albumin levels in BALF also significantly correlated with $\mathrm{HGF}(\mathrm{p}<0.0005), \mathrm{LDH} /$ albumin $(\mathrm{p}<0.0005)$, CEA/albumin ( $p<0.001)$, CA19-9/albumin $(p<0.005)$, SCC/ albumin $(\mathrm{p}<0.05)$ and $\operatorname{IgA} /$ albumin levels $(\mathrm{p}<0.005)$ in BALF. Tumour markers are believed to be released from lung epithelial cells and secretory $\operatorname{IgA}$ is produced by the epithelial cells of the respiratory tract [21]. MuKAE et al. [22] showed that CA19-9 levels are high in serum and BALF of patients with IPF, PF-CVD, bronchiectasis, and diffuse panbronchiolitis. In addition, in the immunohistochemical study, it was shown that the antigen was expressed in bronchiolar epithelial cells and in regenerating epithelial cells [22]. It has also been reported that $\operatorname{IgA}$ in BALF correlates with changes in the diffusing capacity of the lung in pulmonary sarcoidosis [23]. In addition, $\operatorname{IgA}$ in BALF is also increased in patients with hypersensitivity pneumonitis [24]. This evidence suggests that $\operatorname{IgA}$ in
BALF may be a parameter of disease activity in interstitial lung diseases. If epithelial cells are damaged by destructive factors such as elastase [25], it is possible to consider that LDH, CEA, CA19-9, and IgA are released from epithelial cells and represent the degree of epithelial cell damage.

In addition, it was also demonstrated that E-PI/albumin in BALF correlated with the total number of alveolar macrophage/albumin end total number of neutrophil/albumin in BALF. Alveolar macrophages have been shown to release neutrophil chemotactic factors on stimulation with various stimuli, e.g. bacteria, dust grains, cotton, asbestos, and the immune complex [26]. It could be suggested that alveolar macrophage-derived neutrophil chemotactic factors play a role in neutrophil infiltration [26]. Then, the infiltrated neutrophil might release neutrophil elastase.

It was also aimed to evaluate the significance of E-PI as a prognostic factor. Since the follow-up period of our patient population was not long enough, data are not available at present. In addition, the usefulness of the measurement of E-PI in comparison with other inflammatory cytokines in pulmonary fibrosis (interleukin (IL)- $1 \beta$, IL-1 receptor antagonist, soluble IL-2 receptor, IL-6, IL-8, tumour necrosis factor- $\alpha$, and interferon- $\gamma$ ) and correlations between E-PI and these markers should be evaluated in the future study.

In conclusion, the data demonstrate that: 1) elastase: alpha-1 proteinase inhibitor complex in serum is increased in patients with pulmonary fibrosis; and 2) elastase: alpha-1 proteinase inhibitor complex serum and bronchoalveolar lavage fluid correlated with clinical parameters in pulmonary fibrosis. These results suggest that neutrophil elastase may play a role in the process of lung injury and repair in pulmonary fibrosis.

Acknowledgements: The authors would like to thank A. Aoki and the staff of Matsuyama Citizen Hospital Laboratory for their technical assistance throughout the study.

\section{References}

1. Crystal RG, Bitterman PB, Rennard SI, Hance AJ, Keogh BA. Interstitial lung diseases of unknown cause. Disorders characterized by chronic inflammation of the lower respiratory tract. $N$ Engl J Med 1984; 310: 154-166.

2. Peterson MW, Monick M, Hunninghake GW. Prognostic role of eosinophils in pulmonary fibrosis. Chest 1987; 92: 51.

3. Haslam PL, Turton CWG, Lukoszek A, et al. Bronchoalveolar-lavage fluid cell counts in cryptogenic fibrosing alveolitis and their relation to therapy. Thorax 1980; 35: 328-329.

4. Rudd RM, Haslam PL, Turner-Warwick M. Cryptogenic fibrosing alveolitis: relationships of pulmonary physiology and bronchoalveolar lavage to response to treatment and prognosis. Am Rev Respir Dis 1981; 124: 1-8.

5. Hallgren R, Bjermer L, Lundgren R, Venge P. The eosinophil component of the alveolitis in idiopathic pulmonary fibrosis. Am Rev Respir Dis 1989; 139: 373-377.

6. Watters LC, Schwartz MI, Cherniack RM, et al. Idiopathic pulmonary fibrosis. Pretreatment bronchoalveolar ravage cellular constituents and their relationships with lung histopathology and clinical response to therapy. $\mathrm{Am}$ Rev Respir Dis 1987; 135: 696-704. 
7. Turner-Warwick M, Haslam PL. The value of serial bronchoalveolar lavages in assessing the clinical progress of patients with cryptogenic fibrosing alveolitis. Am Rev Respir Dis 1987; 135: 26-34.

8. Hunninghake GW, Kawanami O, Ferrans VJ, Roberts WC, Crystal RG. Characterization of the inflammatory and immune effector cells in the lung parenchyma of patients with interstitial lung disease. Am Rev Respir Dis 1981; 123: 407-421.

9. Fick RB, Naegel GP, Aquier S, Wood RE, Gee JBL, Reynolds HY. Proteins of the cystic fibrosis respiratory tract: fragmented immunoglobulin $\mathrm{G}$ opsonic antibody causing defective opsophagocytosis. J Clin Invest 1984; 74: 236-248.

10. Fujita J, Nakamura H, Yamagishi Y, Yamaji Y, Shiotani $\mathrm{T}$, Irino S. Elevation of plasma truncated elastase $\alpha$ 1-proteinase inhibitor complexes in patients with inflammatory lung diseases. Chest 1992; 102: 129-134.

11. Fujita J, Nelson NL, Daughton DM, et al. Evaluation of elastase and antielastase balance in patients with chronic bronchitis and pulmonary emphysema. Am Rev Respir Dis 1990; 142: 57-62.

12. Evans MD, Pryor WA. Cigarette smoking, emphysema, and damage to $\alpha$ 1-proteinase inhibitor. Am J Physiol 1994; 266: L593-L611.

13. Lee CT, Fein AM, Lippmann M, Holtzman H, Kimbel P, Weinbaum G. Elastolytic activity in pulmonary lavage fluid from patients with adult respiratory distress syndrome. N Engl J Med 1981; 304: 192-196.

14. McGuire WW, Spragg RC, Cohen AB, Cochrane CG. Studies on the pathogenesis of the adult respiratory distress syndrome. J Clin Invest 1982; 69: 543-553.

15. Borzi RM, Grigolo B, Meliconi R, et al. Elevated serum superoxide dismutase levels correlate with disease severity and neutrophil degranulation in idiopathic pulmonary fibrosis. Clin Sci Colch 1993; 85: 353-359.

16. Garcia JG, James HL, Zinkgraf S, Perlman MB, Keogh BA. Lower respiratory tract abnormalities in rheumatoid interstitial lung disease. Potential role of neutrophils in lung injury. Am Rev Respir Dis 1987; 136: 811-817.
17. Raghu G. Interstitial lung disease: a diagnostic approach. Are CT scan and lung biopsy indicated in every patients? Am J Respir Crit Care Med 1995; 151: 909-914.

18. Neumann S, Hennrich H, Gunzer G, Lang H. Enzymelinked immunoassay for human granulocyte elastase in complex with $\alpha$ 1-proteinase inhibitor. In: Horl WH, Heidland A, eds. Proteases: Potential Role in Health and Diseases. New York, Plenum. Publishing Corp, 1984; pp. 379-390.

19. Neumann S, Gunzer G, Hennrich N, Lang $H$. "PMN-elastase assay": enzyme immunoassay for human polymorphonuclear elastase complexed with $\alpha$ 1-proteinase inhibitor. J Clin Chem Clin Biochem 1984; 22: 693.

20. The BAL Cooperative Steering Committee. Bronchoalveolar lavage fluid and venous blood constituents in idiopathic pulmonary fibrosis and selected comparison groups. Am Rev Respir Dis 1990; 141: S188-192.

21. Horie S, Higashihara E, Nutahara K, et al. Mediation of renal cyst formation by hepatocyte growth factor. Lancet 1994; 344: 789-791.

22. Mukae H, Hirota M, Kohno S, et al. Elevation of tumorassociated carbohydrate antigens in patients with difuse panbronchiolitis. Am Rev Respir Dis 1993; 148: 744-751.

23. Hojo S, Fujita J, Yamadori I, Kishimoto T, Yamagi Y, Takahara J. Serial measurement of the plasma hepatocyte growth factor in pneumonia patients who received cancer chemotherapy. J Infect Chemother 1995; 2: 49-51.

24. Matsumoto K, Okazaki H, Nakamura T. Up-regulation of hepatocyte growth factor gene expression by interleukin-1 in human skin fibroblasts. Biochem Biophys Res Commun 1992; 188: 235-243.

25. Defrances MC, Wolf HK, Michalopoulos GK, Zarnegar REZA. The presence of hepatocyte growth factor in the developing rat. Development 1992; 116: 387-395.

26. Ozaki T, Hayashi H, Tani K, Ogushi F, Yasuoka S, Ogura T. Neutrophil chemotactic factors in the respiratory tract of patients with chronic airway diseases or idiopathic pulmonary fibrosis. Am Rev Respir Dis 1992; 145: 85-91. 